\title{
Guerra fría, exilio y redes masónicas en América Latina: Notas preliminares en torno a la logia Soarele Romaniei (Buenos Aires, 1952-1958)
}

\author{
Cold War, Exile and Masonic Networks in Latin America: \\ Preliminary notes on the Soarele Romaniei Lodge (Buenos Aires, \\ 1952-1958)
}

\author{
Dévrig Mollès \\ Universidad de Estrasburgo, Francia \\ devrigmolles@gmail.com
}

Recepción: 14 de febrero de 2018/Aceptación: 24 de abril de 2018.

doi: https://doi.org/10.15517/rehmlac.v10i1.32424

Palabras clave

Guerra fría; exilios; migraciones; sociabilidades; Argentina; Rumania; Armenia.

Keywords

Cold War; Exiles; Migrations; Sociability; Argentina; Romania; Armenia.

Resumen

En 1952, exiliados y emigrados rumanos fundaron en Buenos Aires una logia, en el seno de una de las organizaciones masónicas argentinas de la época. Este grupo reunía a veteranos, personas que habían atravesado la primera guerra mundial, el entre-guerras y la segunda guerra mundial. Rumania estaba entonces en disputa entre las potencias occidentales y las orientales. El momento político era particular en el plano internacional (los inicios de la guerra fría), en el plano continental (el panamericanismo y el anticomunismo), en el plano nacional (el primer peronismo). En la masonería argentina, este contexto pareció reflejarse con la aparición de una nueva camada de logias: ¿logias de exilio? ¿logias de guerra fría? Estas notas de investigación son un primer acercamiento. Pretenden alimentar una investigación en curso para una sociología histórica de las redes masónicas atlánticas y latinoamericanas, de la guerra de 31 años a la guerra fría (19141960).

\section{Abstract}

In 1952, Romanian exiles and emigres founded a lodge in Buenos Aires, within one of the Argentinean masonic organizations of that time. This group was composed of war veterans, people who had been through the First World War, the interwar period and the Second World War. At that stage western and eastern powers were disputing over Romania. It was a peculiar moment at an international level (the beginning of the Cold War), at a Latin American continental level (pan Americanism and anticommunism) and at an Argentinian national level (Peron's first government). Within Argentina's Freemasonry, this context seemed to have started a batch of new lodges; lodges of exiles? Cold War lodges? These preliminary notes are part of our current research on the sociological history of Latin America and the Atlantic masonic networks, from the Second Thirty Year War to the Cold War (1914-1960). 


\section{Introducción}

En 1952, extranjeros radicados en la Argentina fundaron en Buenos Aires una logia que, bajo el título distintivo de Soarele Romaniei (Sol de Rumania), integró la Gran Logia de la Masonería Argentina, una de las federaciones masónicas argentinas de la época ${ }^{1}$. Los archivos localizados son escasos ${ }^{2}$. ¿Cuál es el posible interés de este grupo humano?

En una temporalidad larga, se insertaba en una tradición cosmopolita que -nacida en Europa occidental en el siglo XVIII ${ }^{3}$, diseminada por los puertos y las rutas de expansión y de migración europeas ${ }^{4}$, se había arraigado en Uruguay, Chile y Argentina alrededor de $1850^{5}$.

En una temporalidad más corta, los fundadores de este grupo habían nacido en Rumania, Grecia y Turquía. Habían atravesado la primera guerra mundial, el período de entreguerras y la segunda guerra mundial. En su mochila cargaban esta guerra de treinta-yun años (1914-1945). También parecían cargar el peso de la guerra fría, incipiente y candente. Algunos de ellos se consideraban como "exiliados" y uno se declaraba "apátrido". Sus círculos de sociabilidad no eran anodinos. En efecto, a partir de la Guerra de España, una nueva camada de logias neo-europeas había germinado en el puerto de Buenos Aires y algunos centros urbanos: ¿logias de guerra y exilio? En la década de 1930, veteranos, refugiados y partisanos españoles e italianos habían, por ejemplo, formado sus

1 "Logia Sol de Rumania no. 401: Carta constitutiva", Registro de cartas patentes, Archivo de la Gran Logia

2 Logia Sol de Rumania, "Logia Sol de Rumania n401" (Buenos Aires: Gran Logia Argentina de Libres y Aceptados Masones, 1967 1953), AGLA 1994, 1995. Faltan los libros de actas, aunque fueron remitidos al Archivo de la Gran Logia Argentina en 1958, cuando este grupo se disolvió.

${ }^{3}$ Pierre-Yves Beaurepaire, L'Autre et le Frère, l'Étranger et la franc-maçonnerie en France au XVIIIe siècle (Rennes: Éditions Ouest-France, 1998); Dévrig Mollès, La Invención de La Masonería. Revolución Cultural: Religión, Ciencia y Exilios, Nueva Historia de Las Redes Masónicas Atlánticas 2 (La Plata: Editora de la Universidad Nacional de La Plata, 2015).

4 Cécile Révauger and Éric Saunier eds., La Franc-Maçonnerie Dans Les Ports (Pessac: Presses Universitaires de Bordeaux, 2012); Mollès, "Le Triangle Atlantique: émergence et Expansion de La Sphère Maçonnique Internationale. Une Analyse Statistique (1717-1914)”, Nuevo Mundo Mundos Nuevos 14 (2014), doi: https://doi.org/10.4000/nuevomundo.67498

${ }^{5}$ Felipe Santiago del Solar, Las logias de Ultramar. En torno a los orígenes de la francmasonería en Chile (1850-1862) (Santiago de Chile: Occidente, 2012); Ricardo Martínez Esquivel, "Reseña de Las Logias de Ultramar: En Torno a Los Orígenes de La Francmasonería En Chile, 1850-1862 de Felipe Santiago Del Solar", REHMLAC 5, no. 1 (mayo-noviembre 2013 ): 2 238-255, http://revistas.ucr.ac.cr/index.php/rehmlac/article/view/22498; Mollès, "Exiliados, Emigrados y Modernizadores: El Crisol Masónico Euro Argentino (Europa-Río de La Plata, 1840-1880)", en La Masonería Española: Represión y Exilios, coord. José Antonio Ferrer Benimeli (Zaragoza: Gobierno de Aragón, 2011), 47-70. 
$\operatorname{logias}^{6}$. Estas habían sido seguidas por dos logias neo-alemanas (1941, 1945), dos neogriegas $(1942,1951)$, una neo-checoeslovaca (1943), una neo-inglesa (1943), una neorumana (1952), una neo-israelí (1955), una neo-húngara (1961). El caso de Sol de Rumania se inserta por lo tanto en una cadena más amplia.

Estas logias de guerras y exilios nunca han sido estudiadas. Su interés principal radica en su probable relación con el contexto mundial, regional y nacional. Este texto es un primer acercamiento a esta generación y a este contexto. Tres preguntas lo organizan: Este episodio ¿es un eslabón en una cadena migratoria más vasta? ¿Puede ser relacionado con el exilio (¿liberal?) rumano a inicios de la guerra fría? Finalmente, ¿en qué puede contribuir a una sociología histórica de las redes masónicas atlánticas durante la Guerra de treinta-y-un años y la guerra fría?

El contenido empírico de este fondo documental es, port ahora, relativamente limitado: las fuentes reunidas cuentan como pieza central listados de miembros y correspondencias. Posibilitan un estudio sociográfico y permiten esbozar una biografía colectiva. Lamentablemente, no han sido localizados los libros de actas de esta logia, aunque fueron remitidos al Archivo de la Gran Logia Argentina en 1958, cuando este grupo se disolvió. Éstos nos hubiesen proveído pistas sobre la cultura y la práctica política de este núcleo. ¿Cómo superar este escollo? La conclusión señala y contextualiza una pieza documental notable: se trata de la versión argentina de un libro de Panaï Istrati, un importante intelectual rumano, francófilo y de izquierdas del entre-guerras. Su texto fue presumiblemente editado en Buenos Aires por los que de sus familiares fundaron la logia: ¿nos provee alguna pista?

\section{Un ciclo corto:}

\section{La primera logia Sol de Rumania, Buenos Aires, 1952-1958}

Sol de Rumania fue fundada en 1952, en Buenos Aires, por "un grupo de Masones que" habían "visto de luz masónica en Rumania"7. Algunos habían iniciado su actividad masónica en Europa -antes o después de la segunda guerra mundial; algunos ya tenían en la Argentina una actividad masónica en los años anteriores. Adoptaron el rito escocés antiguo y aceptado, es decir el dispositivo litúrgico mayoritario en el país y en el mundo atlántico. No obstante, introdujeron una pequeña variante, utilizando el idioma rumano y los rituales de la Gran Logia Nacional de Rumania, una pequeña organización disuelta por el gobierno

\footnotetext{
${ }^{6}$ Mollès, "Un Puente Transatlántico: La Masonería Hispano-Argentina En La Circunstancia Euro-Americana de Entre-Guerras", en La Masonería Española En La Época de Sagasta, coord. Ferrer Benimeli (Zaragoza: Universidad de Zaragoza, 2007), vol. 2, 809-842.

7 Juan Istrati, Carta a Domingo R. Sanfeliú, Gran Maestre de la Gran Logia de la Masonería Argentina, 24/07/1952, en AGLA 1994.
} 
rumano a fines de los años 1930. Su primera reunión formal, resumida muy lapidariamente en un acta, expresaba la satisfacción "de haber rendido su homenaje a la G. $\therefore$ D. $\therefore$ G. $\bullet$ A. D. $\therefore$ U. $\because$ y por haber reasumido la actividad masónica, pudiendo así desde este nuevo Taller contribuir en la medida de sus posibilidades para el mayor estrechamiento de vínculos entre argentinos y rumanos",

En el papel, esta "logia de habla rumana" debía contribuir a "la mayor expansión de la Institución" y con el tiempo constituirse "en nuevo faro de luz en medio de las tinieblas de la ignorancia y de la superstición que desagradecidamente aún reinan en el mundo profano",9.

La nueva formación recibió el apoyo político y humano de Pindos no. 388, otra logia nacional-migratoria (griega) regulada por la Gran Logia de la Masonería Argentina. La Buenos Aires no. 348, manifestó su apoyo a través de su presidente -muy probablemente un francés de origen armenio ("Jacques Katichikian""10). Las operaciones fueron rápidamente concluidas. Poco después, el secretario general de la Gran Logia -un griego miembro de Pindos - informaba al Juan Istrati, el rumano que encabezaba Sol de Rumania. La logia podía comenzar a funcionar y a integrar nuevos miembros ${ }^{11}$. En 1953 , un año después, fue formalmente incorporada bajo el n401 por la Gran Logia de la Masonería Argentina $^{12}$. Adoptó el rito escocés antiguo y aceptado, dominante en el país. No obstante, se usaría una versión peculiar del mismo, en rumano, editada por la Gran Logia Nacional de Rumania ${ }^{13}$ : se remetía entonces necesariamente a un documento editado antes de 1939, fecha de disolución de la masonería en Rumania por el gobierno. El ciclo de vida de Soarele Romaniei fue corto (1952-1958) ${ }^{14}$. A fines de la década de 1960, algunos de sus miembros unidos a otras personas reconstituyeron una logia con este nombre y este número; no se los estudiará aquí.

\footnotetext{
${ }^{8}$ Logia Sol de Rumania, 14/07/1952, Acta no. 1 (AGLA 1994)

${ }^{9}$ Logia griega Pindos no. 388, Carta a Domingo R. Sanfeliú, Gran Maestre de la Gran Logia de la Masonería Argentina, 17/07/1952, en AGLA 1994

${ }^{10}$ Logia Buenos Aires no. 348, Carta a Domingo R. Sanfeliú, Gran Maestre de la Gran Logia de la Masonería Argentina, 14/08/1952, en AGLA 1994

${ }^{11}$ Alcibíades Lappas, Carta a Juan Istrati, Buenos Aires, 31 de agosto de 1952 (AGLA 1994)

${ }^{12}$ Por resolución de su comité central (el "Consejo de la Orden”) el 18 de agosto de 1953: Carta constitutiva de la Resp. : Logia Sol de Rumania de la ciudad de Buenos Aires, 18/08/1953, Registro de Cartas patentes, fol. 305, Buenos Aires: Archivo de la Gran Logia Argentina (AGLA 277).

${ }^{13}$ Logia Sol de Rumania, 14/07/1952, Acta no. 1 (AGLA 1994)

${ }^{14}$ La logia anunció su disolución, después de tratar de frenar su declive debido a la "deficiente asistencia de los HH. $\because$ a los trabajos del Tall. $\because$ ” y a querellas internas, aludidas en una carta: Logia Sol de Rumania / Logia Soarele Romaniei, Carta a la Gran Logia de la Masonería Argentina, Buenos Aires, 05/05/1958 (AGLA 1994)
} 


\section{El público de Sol de Rumania}

¿Qué público reunió Soarele Romaniei? La documentación es árida, pero permite esbozar un retrato.Ante que todo, este público fue escaso. Oficialmente, el núcleo fundador reunió a 9 hombres (14 de julio de 1952). En 1956, el círculo reunía una quincena de miembros $^{15}$. En 1957, no reunía más de nueve maestros-masones, más un pequeño número de aprendices y compañeros ${ }^{16}$. En total, poco más de treinta hombres pasaron por Sol de Rumania entre 1952 y 1958. Se trataba de una logia pequeña, situada en el promedio argentino de esta época.

$\mathrm{Su}$ constitución generacional era significativa. La gran mayoría había crecido a la sombra de la primera guerra mundial. Seis miembros habían nacido entre 1891 y 1898 y, entre los cuales dos fundadores; tenían entre 23 y 16 años en $1914^{17}$. De los demás, 17 habían nacido entre 1900 y 1918, y 7 entre 1919 y $1925^{18}$. Al finalizar la segunda guerra mundial, en 1945, estos hombres tenían de 20 a 54 años.

Sol de Rumania era una logia nacional-migratoria. Desde el siglo XIX, las logias nacional-migratorias eran un formato típicamente latinoamericano ${ }^{19}$. Destinada a una comunidad extranjera, tal tipo de logia se encontraba regulada por una organización masónica nacional. Sol de Rumania estaba instalada en el territorio argentino y, federada a la Gran Logia de la Masonería Argentina (Cangallo 1242, Buenos Aires), emanaba y se dirigía en prioridad a un público extranjero. Salvo una excepción, ninguno era argentino de nacimiento. Según los datos parciales disponibles, la mayor parte había llegado después de la segunda guerra mundial, especialmente entre 1948 y 1953.

¿De dónde venían? Un solo había nacido en la Argentina (en Haedo, Buenos Aires), probable descendientes de rumanos (Eduardo H. Ororbia). Otros 17 miembros sus raíces en Rumania (de los cuales cinco fundadores), algunos en Grecia y en Turquía, de Francia y de dos colonias francesas: Siria y Argelia. ¿Qué los unía, además de su condición de exiliados o emigrados? Los apellidos de los nueve fundadores se repartían entre dos familias

\footnotetext{
1514 miembros según una carta del 19/11/1956 (AGLA 1994).

${ }^{16}$ Carta del 01/04/1957 (AGLA 1994).

${ }^{17}$ Constantino Vallimaresco (1891): Radu Cutzarida (1894); Juan Istrati (1894, primer presidente de la logia); Isidoro Berger-Safiano (1897); Juan Stanculescu (1898).

${ }^{18}$ Algunos no informaron estos datos. Sergio Lazarov (1901); Léon Weiner (1901); Hariton Kazakian, 1902; Nicolas Duca, 1906; Ion Voinea (1906); Onicazian Papazian (1908); Paul Manouk Manoukian, 1912; Malhas Kergham (1913); Miguel Cioc, 1914; Miron Stefenescu, 1914; Dikran Kozalyan (1914); Peiruz Manouk Manoukian, 1915; Kiragos Sakazlian (1915); Alejandro Scherer (1917); Elie Trifu (1917); Ilie Valentín Boros (1917); Dumitru Cottescu (1919); Vahe Merdinian (1920); Atamian Haig (1920); Georges Istrati (1921); Mircea Ghitia (1921); Eduardo Héctor Ororbia (1921); Puzant Guemdjian (1925).

${ }^{19}$ Mollès, "Triangle atlantique et triangle latin: l'Amérique latine et le système-monde maçonnique (17171921) (Éléments pour une histoire des opinions publiques internationales)" (Tesis de doctorado en historia, Université de Strasbourg, 2012).
} 
lingüísticas: una nítidamente rumana ${ }^{20}$ y otra muy probablemente armenia ${ }^{21}$. Estas dos corrientes también dominaban la nómina completa de los afiliados, aunque ésta integraba también apellidos griegos y franceses; el miembro argelino llevaba un nombre probablemente armenio: Haig Atamian.

Estos migrantes se integraron rápidamente a la nación cívica argentina, sin por ello abandonar su exótico cosmopolitismo. Al constituirse la logia en 1952, cinco Rumanos integraban el núcleo fundador; de ellos, cuatro ya habían obtenido su carta de ciudadanía argentina (dos informaban residir desde 1948 en Buenos Aires); la única excepción era el presidente de la logia, un Rumano de 58 años (quien en su ficha había anotado "Argentino" para luego borrarlo y escribir "Rumano"). Del total de los miembros, por lo menos 12 adoptaron la nacionalidad argentina: 1 Francés (Isidore Berger-Safiano, radicado en 1948), 10 Rumanos y 1 Turco. Es posible que los demás hayan seguido el mismo camino sin documentarlo en este expediente. En sus peregrinaciones, otros habían adquirido nacionalidades exóticas. Tres manifestaban tener la nacionalidad iraní; era el caso de Atamian Haig, un industrial nacido en la Argelia francesa en 1920; era el caso también de Peiruz Manouk Manoukian y Vahe Merdinian, un comerciante y un industrial nacidos en Estambul en 1915 y 1920; curiosamente, Peiruz tenía en la logia un hermano o un primo también miembro fundador- nacido en 1912 en... Atenas (Grecia) y detentor de la nacionalidad griega. Finalmente, Hariton Kazakian -un industrial nacido en Andrinópolis (Grecia) en 1902- declaraba la nacionalidad venezolana. Mencionemos finalmente el caso de Puzant Gemdjian, un joyero nacido en Beyrouth (Líbano) en 1925, quien se declaraba apatrido.

Estos hombres eran casados en su gran mayoría. Poseían cierto capital cultural. Varios eran profesionales dotados de un nivel de estudios poco común por entonces: médicos, abogados, ingenieros, aviadores, marineros y diplomáticos por ejemplo; un artista, un artesano y algunos empleados completaban el cuadro. Entre los fundadores predominaba cierto perfil sociológico que se consolidó y diversificó un poco en el tiempo. Según los datos disponibles, el ingreso mensual más era de $1000 \$$ y el más alto de $4000 \$$ (moneda nacional). En 1955, la logia manejaba una caja propia de 5000\$ (moneda nacional), equivalente quizás a dos meses del ingreso promedio de sus miembros ${ }^{22}$. Predominaban los comerciantes, entre los cuales un fuerte núcleo de presuntos Armenios turco-iranios y libaneses (especializados en el textil y la joyería) ${ }^{23}$. Varios se decían industriales ${ }^{24}$, médicos

\footnotetext{
${ }^{20}$ Lamentablemente, sus nombres habían sido hispanizados: Juan Istrati, Miguel Cioc, Nicolás Duca, Miron Stefenescu, Juan Stanculescu.

${ }^{21}$ Hariton Kazakian, Paul Manouk Manoukian, Peiruz Manouk Manoukian, Vahe Merdinian.

${ }^{22}$ Carta del 19/05/1956 (AGLA 1994).

${ }^{23}$ Entre los fundadores, solo eran dos: los dos Manouk Manoukian -respectivamente Griego y Turco-Iraní.

${ }^{24}$ el Rumano Juan Istrati, el Griego-Venezolano Hariton Kazakian y el Turco-Iraní Vahe Merdinian.
} 
y abogados ${ }^{25}$. Integraban el grupo un capitán de ultramar, un coronel aviador, un mecánico aviador $^{26}$. Dos diplomáticos llamaban la atención. Constantino Vallimaresco -nacido en 1891, casado con Maria Penescu, licenciado en derecho- era "ex diplomático (ministro plenipotenciario)" reconvertido al comercio. Radu Cutzarida -nacido en Bucarest en 1894, casado con Rosemarie y padre de tres hijos- se declaraba, en el momento de su afiliación, "diplomático, encargado y ministro plenipotenciario"; no precisaba que gobierno representaba: ¿algún gobierno rumano en exilio?

¿Cómo habían llegado a la masonería? Es imposible adivinarlo. Pero algunos tenían cierta antigüedad. Solo una pequeña minoría tuvo su primera experiencia masónica en esta logia. El acta fundacional del 14 de julio de 1952 ya mencionaba algunos de estos "masones regulares según acreditan con la pertinente documentación a la vista y deseosos de reanudar su actividad masónica"27. Varios miembros habían tenido una actividad masónica en Rumania antes de la Guerra. Juan Istrati, el presidente, agregaba a su firma un símbolo ("33..") por el cual manifestaba haber cursado todos los escalones del Rito escocés antiguo y aceptado; lamentablemente, no daba más información ${ }^{28}$. Era el caso del francés Isidore Berger-Safiano, nacido en 1897 e iniciado en 1924 en el "Gran Oriente de rito escocés en Rumania, Bucarest", promovido al grado 3 en 1939, "muy poco antes de haber cerrado el Gobierno rumano las Logias y confiscado todos los archivos" (AGLA 1994). El griego Nicolas Xinos, llegado en 1952 con esposa e hija, había sido de la logia Renasterea de Bucarest, en 1925, sin frecuentarla mucho.

Otros habían tenido actividad masónica en Rumania después de la Guerra, en el breve lapso que separó la Liberación de la Sovietización. Tenían, en este momento, alrededor de 30 o 45 años. El coronel Juan Stanculescu y el capitán de ultramar Miron Stefenescu habían integrado la logia Eleusis, de Bucarest, respectivamente en 1944 y en 1946 (ambos llegaron en Argentina en 1948 y se naturalizaron). En 1946-1947, los dos diplomáticos se habían sumado, respectivamente, a la logia Romania Unita (en el caso de Constantino Vallimaresco) y Dacia (en el caso deRadu Cutzarida). En la misma época, el médico Miguel Cioc había sido recibido por la logia Isis en Bucarest, tal como el joyero Onic Papazian (quien ostentaba el grado 18 del Rito "escocés"). Su probable hermano (de

\footnotetext{
${ }^{25}$ Por ejemplo el abogado Rumano-Argentino Nicolás Duca; el médico Rumano-Argentino Miguel Cioc.

${ }^{26}$ El marino rumano-argentino Miron Stefenescu, nacido en 1914 en Bucarest, era bachiller de Escuela naval, capitán de ultramar de la Marina rumana y en aquella época oficial de la marina mercante (Compañía Shell Mex. S.A.); Juan Stanculescu, nacido en 1898 en Bucarest, era "Coronel aviador, técnico aeronaútico y piloto inspector" formado en distintas "Escuelas superiores de aeronaútica", empleado como aviador en el ministerio de Aeronaútica ("DGAC": Dirección General de la Aviación Civil?). Dutmitru Cottescu era aviador y mecánico (precisaba "liceo y bachiller"); había llegado en 1949.

${ }^{27}$ Logia Sol de Rumania, 14/07/1952, Acta no. 1 (AGLA 1994)

${ }^{28}$ Recorrido que en los países latinos exige habitualmente una década o más. A la diferencia de Estados Unidos, donde en la actualidad puede comprarse el grado 32 en una semana, siendo el grado 33 un poco más difícil de adquirir (ignoro si era el caso en 1950).
} 
sangre), también había sido masón de Iubirea de Patrie entre 1946 y 1949 ante de embarcar para la Argentina en 1952, con su esposa Anahit y sus dos hijos de 4 y 7 años; se afilió un mes después a la logia rumana de Buenos Aires. Poco después llegó un correligionario suyo: Dykran Kozalyan, también miembro de Iubirea de Patrie entre 1946 y 1949; este comerciante turco desembarcó en 1953 en Argentina, con su esposa Hripsimia y sus 3 hijos, para afiliarse a la logia rumana 8 meses después, a la edad de 40 años. Finalmente, Haig Atamian -el industrial franco-argelino-iraní- había integrado la Grande Loge de France en 1950, a la edad de 30 años; radicado en 1952 en Argentina; su condición de próspero empresario armenio (diplomado de la Academia mundial de comercio, de Viena) quizás explica su afiliación a Soarele Romaniei, en 1954.

\section{La actividad aparente de Soarele Romaniei}

La documentación conservada ofrece poco sobre la actividad de Soarele Romaniei. Dos elementos parecen merecer un pequeño comentario aquí: una tentativa para reunirse con la diáspora rumana y una fibra liberal y anticomunista.

Una modesta tentativa para organizar la diáspora rumana a través de las redes masónicas

Una de las primeras preocupaciones de la logia fue la diáspora rumana. Para reunir lo disperso, Juan Istrati y el núcleo duro de la logia recurrieron a las redes masónicas. ¿Cuáles fueron los resultados aparentes?

Durante el primer semestre 1953, Alkis D. Lappas -griego y entonces El secretario general de la Gran Logia de la Masonería Argentina- se comunicó con "las Grandes Logias de Chile, Uruguay, Río de Janeiro, Holanda, Francia, Italia, Austria, Alemania, Nueva York", solicitando ayuda para localizar "rumanos en el exilio"29. Algunos meses después, los resultados eran mitigados. En Chile, ningún masón rumano "salvo que los existentes figuren con otra nacionalidad". Uruguay y Francia aún no habían contestado. En Holanda, se había publicado un aviso en la revista masónica. Italia señalaba que "pasaron varios masones rumano pero no hay constancia de que se hallan afiliados a Logias italianas". En Austria, había "algunos masones rumanos pero muy pocos". De Alemania, informaban "que en los cuadros lógicos no aparecen masones de nacionalidad rumana" ${ }^{30}$. Como se ve, los resultados parecen haber sido magros. Aún así, la tentativa reviste un doble interés: por un lado, las redes masónicas permitían efectivamente a un puñado de exiliados y emigrados

\footnotetext{
${ }^{29}$ Alcibiades Lappas, Carta a Juan Istrati, presidente de la logia Sol de Rumania, Buenos Aires, 21/04/1953 (AGLA 1994)

${ }^{30}$ Alcibíades Lappas, Carta a Juan Istrati, 10/06/1953 (AGLA 1994)
} 
intentar comunicarse con su diáspora; en el contexto de pos-guerra, ello seguramente no era al alcance de los millones de desterrados que circulaban por el mundo.

Por otra parte, una cadena de correspondencia conservada en el prontuario de Sol de Rumania permite seguir esta inquietud en Europa. El 21 de abril de 1953, Alkis D. Lappas solicitaba a Ernst F. J. Plaut ${ }^{31}$, un masón germano-argentino. Le pedía ayudar Sol de Rumania a "entrar en contacto con masones rumanos de otras partes a fin de estrechar vínculos e intercambiar informaciones sobre parientes y personas amigas". Debía par ello recurrir a sus "corresponsales de Alemania, Holanda y Suiza"32. Tres semanas después, Plaut ya había recibido noticias "del Ven.. Hno. $`$ J. J. van der Laan”. Este holandés 33 averiguaría la presencia de "hermanos rumanos en Holanda"; informaría en su revista masónica, aparentemente importante en esta época para estos círculos, que una logia rumana había sido fundada en Buenos Aires ${ }^{34}$. Diez días después, Plaut daba un nuevo informe. El hermano Karl Kraus -su correspondiente de Viena- le había contestado. Estaba de viaje. Acompañaba el presidente del Supremo Consejo de Viena a una "reunión de los Sob. $\cdot$ Gr. $\cdot$ Comm. $`$ europeos". Estos presidentes del Rito escocés antiguo y aceptado en Europa eran necesariamente los representantes de algunos países de Europa del Oeste donde la masonería no había sido destruida (Reino Unido, Suiza) o donde se estaba reconstituyendo (Francia, Bélgica, Italia). No obstante, algunos masones rumanos asistirían a la reunión; además, un miembro de su propia "logia azul" (su unidad básica) había sido iniciado en Rumania (le proveía su dirección). El lenguaje podría ser codificado, como podría no serlo. Lo llamativo es que anunciaba el envío de otro "correo común" (no por vía área). Plaut lo explicaba para "eludir la censura rusa"35. Poco después, Karl Kraus enviaba de la Viena ocupada por los Rusos nuevos datos de contacto ${ }^{36}$.

${ }^{31}$ Plaut era entonces venerable-maestro de la logia germánica Unitas y entonces miembro de la comisión de Relaciones exteriores de la Gran Logia, que el propio Lappas presidiría durante los años 1970.

${ }^{32}$ Alcibiades Lappas, Carta a Ernest F. J. Plaut, Buenos Aires, 21/04/1953 (AGLA 1994).

${ }^{33}$ Cuyo título protocolar indicaba que ocupaba o había ocupado la presidencia de una logia de base.

${ }_{35}^{34}$ Ernest F. J. Plaut, Carta a Alcibíades Lappas, 09/05/1953 (AGLA 1994).

${ }^{35}$ Ernest F. J. Plaut, Carta a Alcibíades Lappas, 20/05/1953 (AGLA 1994). Precisaba a destinación de los hermanos de Sol de Rumania: "los contactos que tomé a vuestro pedido están dando un resultado".

${ }^{36}$ Ernest F. J. Plaut, Carta a Alcibíades Lappas, 06/06/1953 (AGLA 1994). "En Viena y en la Austria-Baja, tenemos una censura de la correspondencia, es decir en aquellas partes en que los Rusos solos (Austria Baja) o conjuntamente con los Americanos, Ingleses y Franceses ejercitan el poder de ocupación. Esta, sin embargo, ya no existe más desde hace mucho tiempo en las partes ocupadas por las otras tres potencias de ocupación. Posiblemente una u otra de las cartas no ha pasado por esta censura. Por ello, le día al hermano Sattler una dirección por intermedio de la cual las cartas me llegan sin censura. Ella es: Dr Erich Blumberg, für Karl Kraus, Dinghoferstrasse 39, Linz a. d. Donau (Oberösterreich). Por esta dirección, las cartas me llegan con toda regularidad $[\ldots]$ sin pasar por la censura de Viena". 


\section{Una cultura política liberal y anticomunista}

¿Cuál era la cultura política de los miembros de Sol de Rumania? Los indicios son escasos pero bastante claros.

En primer lugar, la fecha del acta de la primera reunión -el 14 de julio de 1952difícilmente fue casual. Rumania se había constituida como Estado-nación durante el siglo XIX, a partir de una cultura política fuertemente influenciada por el modelo francés. Durante el periodo de Entre-Guerras, Rumania integraba la "pequeña alianza" sobre la cual descansaba parte de la estrategia defensiva de Francia ante el creciente poder de Alemania $^{37}$. Soarele Romaniei estaba unida a este pasado por hilos biográficos. Ilie Valentín Boros, por ejemplo, poseía el grado de capitán de l'École Spéciale Militaire de Saint-Cyr, una de las principales escuelas militares francesas; nacido en 1917 en Moldavia, tenía durante su formación unos veinte años: había sido de los últimos oficiales rumanos formados en Francia antes de la guerra ${ }^{38}$. En la logia estaba un francés llegado en 1948 y naturalizado: Isidore Berger-Safiano -técnico en la industria textil, quien en 1954 se mudó a Chile solicitando su pasaporte masónico ${ }^{39}$. Onic Papazian se había licenciado en Sciences Commerciales en Anvers, Bélgica. Sergio Lazarov - un rumano nacido en 1901- había cursado la École du Génie Civil, des Arts et Manufacture de Gand, Bélgica.

Otro rasgo permite situar el perímetro cultural y político dentro del cual se movía Soarele Romaniei. La Gran Logia de la Masonería Argentina - una de las organizaciones masónicas argentinas de la época- se definía entonces por un liberalismo conservador y por su inserción en el eje geocultural dominado por la United Grand Lodge of England ${ }^{40}$. Sus documentos traducían esta cultura en términos religiosos y jurídicos. Las solicitudes de afiliación, por ejemplo, especificaban:

Venerable Maestro, El que suscribe, Maestro Masón, declara haber explicado claramente al interesado los principios y fines de la Institución, así como que la Masonería rechaza a todo individuo que se declara ateo y no reconoce la existencia del GADU y la inmortalidad del alma. Además, que la Institución no es una sociedad de socorros mutuos, ni una agencia de colocaciones, que los beneficios que se puede esperar de la misma son sólo aquellos tendientes al mejoramiento moral e intelectual como también haberle manifestado que se exige el respeto a la Ley, a la Constitución y a los Poderes legalmente constituidos, principios fundamentales establecidos en la Masonería Universal (AGLA 1994).

\footnotetext{
37 Jean-Baptiste Duroselle, La Décadence (1932-1939) (París: Imprimerie Nationale - Institut d'Histoire des Relations Internationales contemporaines - Académie des Sciences morales et politiques, 1985), 560.

${ }^{38}$ En Argentina, donde llegó en una fecha no precisada, se naturalizó y se hizo comerciante de materiales para soldar, con un ingreso mensual de $3000 \$$ aprox.

${ }^{39}$ Estaba casado con Clara Schwartz de Berger Safiano, y tenía dos hijos de 25 y 27 años, ingenieros textil.

${ }^{40}$ Mollès, "Un Puente Transatlántico."
} 
En el contexto de la guerra fría, este texto cobraba un matiz particular. Se perfilaba claramente una adhesión moral al gran frente anticomunista de los años 1950. Fundada por rumanos, ¿se integraba también Soarele Romaniei en este frente anticomunista? El 7 de noviembre de 1956, la logia enviaba una carta a la Gran Logia de la Masonería Argentina para manifestar una auténtica indignación anticomunista. El contexto emocional era doble: por un lado la guerra fría y la primavera de Praga; por otro lado la revolución libertadora y la proscripción del peronismo en Argentina. No obstante, definiéndose como "Rumanos que tenemos la dicha de vivir en un país libre y democrático", los firmantes no aludían sino a una acción del "gran pueblo argentino" y de la "masonería argentina [...] contra las dictaduras y especialmente [...] contra la barbarie comunista":

Venerables y Muy Queridos Hermanos. Tenemos el agrado de dirigirnos a esta augusta y respetable Gran Logia a fin de manifestarles nuestro infinito agradecimiento por todo lo que el gran pueblo Argentino y la Masonería Argentina han hecho y están haciendo en la lucha contra las dictaduras y especialmente en la lucha contra la barbarie comunista. Nuestro pueblo sufre y se solidariza con los Húngaros. Como Rumanos que tenemos la dicha de vivir en un país libre y democrático, queremos hacer propicia esta oportunidad para poner de manifiesto nuestra entera solidaridad con la lucha que están librando todos los pueblos que viven bajo el yugo comunista $[\ldots]^{41}$.

\section{Líneas de fuga (conclusión)}

\section{Balance}

Este modesto estudio preliminar se centra en un grupo original: la logia Sol de Rumania / Soarele Romaniei, fundada en 1952, disuelta en 1958. Compuesta por menos de 33 miembros, era una típica logia nacional-migratoria, integrada a una masonería nacional pero dirigida a una comunidad migratoria. ¿Cuál es su posible interés para una sociología histórica de las redes masónicas atlánticas durante la guerra fría? La documentación es árida y señala estrechos límites. Los expedientes personales forman su núcleo. Se suman algunas correspondencias significativas con Argentina o con Europa.

Los fundadores habían nacido en Rumania, Grecia y Turquía. Algunos habían iniciado su actividad masónica en Europa -antes o después de la segunda guerra mundial; algunos tenían en la Argentina una actividad masónica. Adoptaron el rito escocés antiguo y aceptado -el dispositivo litúrgico mayoritario en el país y en el mundo atlántico; no obstante, introdujeron una pequeña variante, utilizando el idioma rumano y los rituales de

\footnotetext{
${ }^{41}$ Logia Sol de Rumania / Logia Soarele Romaniei, Carta a la Gran Logia de la Masonería Argentina, Buenos Aires, 07/11/1956 (AGLA 1994)
} 
la Gran Logia Nacional de Rumania, una pequeña organización disuelta por el gobierno rumano a fines de los años 1930. ¿Quiénes eran estos ciudadanos rumanos, venidos del bloque del Este hacia la Argentina a inicios de la guerra fría?

Soarele Romaniei fue una pequeña logia masónica fundada en Buenos Aires en 1952. Se trataba de una típica logia nacional-migratoria: aunque situada bajo la regulación de una organización masónica nacional, su público predilecto era constituido por exiliados y emigrados, oriundos en este caso de los márgenes orientales de Europa.

Internamente, Soarele Romaniei utilizaba el idioma rumano y los rituales publicados por la Gran Logia Nacional de Rumania antes de la segunda guerra mundial. Salvo una excepción, todos sus miembros eran extranjeros. Diecisiete habían arribado a Argentina entre 1948 y 1953 (los quince restantes no dejaron precisiones sobre este aspecto). El núcleo duro de este grupo era rumano; los otros venían de Turquía, Grecia, Siria, Argelia o de Francia. La mayor parte de ellos tendieron a integrarse rápidamente a la nación cívica argentina, adquiriendo la ciudadanía. Algunos ostentaban, en el momento de afiliarse, nacionalidades inesperadas (Venezuela, Irán). Casi todos estos hombres eran casados. Tenían cierto capital cultural, social y económico. Entre las profesiones presentes, se notaban algunos militares y diplomáticos de formación, comerciantes, industriales, marinos, aviadores, ingenieros, diplomáticos, abogados, médicos, artistas, artesanos.

Este círculo abigarrado salía de la "guerra de 31 años" (1914-1945). Parecía haber sido empujado en la ribera platense por los vientos tormentosos de la Primera Guerra mundial, de la Revolución rusa, del desmembramiento del imperio otomano y del imperio austro-húngaro, de la ampliación de la "Gran Rumania" en la órbita francesa ${ }^{42}$, de la crisis de entre-guerras y de la segunda guerra mundial. Todos pudieron haber tenido experiencias militares, políticas o migratorias significativas durante estos periodos. Muchos tenían una experiencia masónica previa, iniciada en Europa en antes o después de la guerra. Algunos se habían conocido allí. En suma, se trataba de una generación adiestrada en un contexto muy particular. La fundación de Sol de Rumania intervino siete años después de la liberación, cuando comenzaba la guerra fría.

El modelo francés era sin duda un elemento central en la cultura política de este grupo. La elección de un 14 de julio por fecha fundacional lo simboliza. Más allá, varios miembros eran egresados de grandes escuelas civiles o militares francesas. Esta francofilia se cristalizaba dentro del perímetro de un liberalismo conservador y anticomunista compartido por los huéspedes argentinos de la Gran Logia de la Masonería Argentina, una organización anglófila.

Los animadores de Soarele Romaniei se percibían a sí mismo como "exiliados", y uno de ellos era oficialmente "apátrido". Apoyados por los dirigentes masónicos

\footnotetext{
${ }^{42}$ Duroselle, La Décadence (1932-1939), 560.
} 
argentinos, procuraron localizar a otros exiliados rumanos en Europa y en América. Su tentativa no parece haber sido muy exitosa, pero enseña como se reactivaban las redes masónicas después de la guerra mundial.

\section{Perspectivas}

Esta base es interesante pero árida. ¿Cómo convertirla en un insumo para una futura sociología histórica de las redes masónicas atlánticas durante la guerra Fría?

En primer lugar, este grupo se presentaba como una asociación comunitaria destinada a exiliados y emigrados oriundos de Europa oriental. Por lo tanto, debe ser resituado en su contexto migratorio. Por un lado, reconstituía antiguas redes de sociabilidad, tejidas antes de la guerra ${ }^{43}$. La presencia de dos o tres redes familiares también parece clara. ¿Fue esta logia una expresión de la inmigración armenia en la Argentina después de la segunda guerra mundial? Varios indicios lo sugieren, desde el apoyo recibido por el presidente de la logia Buenos Aires -muy probablemente un francés de origen armenio ("Jacques Katichikian" ${ }^{\text {,4 }}$, hasta los numerosos apellidos armenios presentes en la nómina de miembros. Para profundizar este aspecto, se podrá recurrir no solo a la bibliografía adecuada sino también a la historia oral, interrogando a los miembros de las logias neoarmenias actuales o al arzobispo armenio en Buenos Aires.

En segundo lugar, es notable la presencia en los archivos de la Gran Logia Argentina de una traducción póstuma de Panait Istrati. Dos de los miembros de la logia (entre los cuales el venerable-maestro y fundador) llevaban el mismo apellido: ¿eran parientes? Panait Istrati había fallecido en 1935 en Budapest. Su obra se considera como una de las más importantes de la literatura rumana, y fue reeditada completa por Gallimard en Paris en 1977. Su legado -en rumano y en francés- fue una trayectoria: compañero de ruta de la Unión Soviética hasta 1927, y luego crítico radical del leninismo, cultivó un humanismo liberal y democrático, preconizando sin esperanzas soluciones parlamentarias y razonadas para construir la "rumanitud" exaltada por las derechas fascistas de los años $1930^{45}$. La edición de su Mi cruzada en Buenos Aires fue casi clandestina: sin fecha, económica, fue quizás organizada durante los años 1950 por la misma logia, como lo sugiere el nombre de la editorial: Armonía ${ }^{46}$.

\footnotetext{
${ }^{43}$ Algunos miembros fueron integrados sobre la base -válida en masonería- de testimonios que daban fe de la condición del postulante, que no poseía la documentación probatoria para justificar su condición

${ }^{44}$ Logia Buenos Aires no. 348, Carta a Domingo R. Sanfeliú, Gran Maestre de la Gran Logia de la Masonería Argentina, 14/08/1952, in AGLA 1994

45 Panait Istrati, Vers l'autre Flamme: Après Seize Mois Dans l'URSS, vol. 3 (Rieder, 1929); Panaït Istrati, Vers l'autre Flamme. Après Seize Mois Dans l'URSS: Confession Pour Vaincus, vol. 57 (Paris: Editions Gallimard, 1987).

${ }^{46}$ Panait Istrati, Mi cruzada (obra póstuma), Traducción del francés o del rumano (?) (Buenos Aires: Armonía, 1956).
} 
Finalmente, se debe evaluar la relación entre esta logia y la geopolítica de la Guerra fría. ¿Fue un nódulo perdido del exilio liberal o anticomunista rumano? La presencia en este pequeño grupo de varios militares y de dos diplomáticos en actividad sugiere vínculos con el gobierno rumano que, en el exilio y con el apoyo de las potencias noratlánticas, aún se mantenía en reserva para una posible alternancia en Rumania, entonces ocupada por el Ejército rojo. Por otra parte, este grupo surgió en un periodo donde varias logias nacionalmigratorias fueron creadas en la masonería argentina: neo-inglesas, neo-francesas, neoitalianas, neo-checoslovacas, neo-griegas, neo-españolas o neo-rumanas, ¿qué significó su fundación, cuáles fueron sus públicos y sus actividades manifiestas?

\section{Bibliografía}

Beaurepaire, Pierre-Yves. L'Autre et le Frère, l'Étranger et la franc-maçonnerie en France au XVIIIe siècle. Rennes: Éditions Ouest-France, 1998.

Duroselle, Jean-Baptiste. La Décadence (1932-1939). París: Imprimerie Nationale - Institut d'Histoire des Relations Internationales contemporaines - Académie des Sciences morales et politiques, 1985.

Istrati, Panaït Mi cruzada (obra póstuma). Traducción del francés o del rumano (?). Buenos Aires: Armonía, 1956.

Istrati, Panaït Vers l'autre Flamme: Après Seize Mois Dans l'URSS. Vol. 3. Rieder, 1929.

Istrati, Panaït. Vers l'autre Flamme. Après Seize Mois Dans l'URSS: Confession Pour Vaincus. Vol. 57. París: Editions Gallimard, 1987.

Loge Sol de Rumania. "Logia Sol de Rumania no. 401." Buenos Aires: Gran Logia Argentina de Libres y Aceptados Masones, 1967 1953. AGLA 1994, 1995.

"Logia Sol de Rumania no. 401: Carta constitutiva." Registro de cartas patentes, Archivo de la Gran Logia Argentina. Buenos Aires: Gran Logia Argentina de Libres y Aceptados Masones, August 18, 1953. AGLA 277.

Martínez Esquivel, Ricardo. "Reseña de Las Logias de Ultramar: En Torno a Los Orígenes de La Francmasonería En Chile, 1850-1862 de Felipe Santiago Del Solar".

$\begin{array}{lllll}R E H M L A C & 5, & \text { no. } & 1 & \text { (2013): }\end{array}$
http://revistas.ucr.ac.cr/index.php/rehmlac/article/view/22498

Mollès, Dévrig. "Exiliados, Emigrados y Modernizadores: El Crisol Masónico Euro Argentino (Europa- Rio de La Plata, 1840-1880)”. En La Masonería Española: Represión y Exilios. Coordinado por José Antonio Ferrer Benimeli. Zaragoza: Gobierno de Aragón, 2011.

Mollès, Dévrig. La Invención de La Masonería. Revolución Cultural: Religión, Ciencia y Exilios. Nueva Historia de Las Redes Masónicas Atlánticas 2. La Plata: Editora de la Universidad Nacional de La Plata, 2015. 
Mollès, Dévrig. "Le Triangle Atlantique: Émergence et Expansion de La Sphère Maçonnique Internationale. Une Analyse Statistique (1717-1914)". Nuevo Mundo Mundos Nuevos 14 (2014). Doi: https://doi.org/10.4000/nuevomundo.67498

Mollès, Dévrig. "Triangle atlantique et triangle latin: l'Amérique latine et le systèmemonde maçonnique (1717-1921) (Éléments pour une histoire des opinions publiques internationales)". Tesis de doctorado en historia, Université de Strasbourg, 2012.

Mollès, Dévrig. "Un Puente Transatlántico: La Masonería Hispano-Argentina En La Circunstancia Euro-Americana de Entre-Guerras". En La Masonería Española En La Época de Sagasta. Coordinado por José Antonio Ferrer Benimeli. Zaragoza: Universidad de Zaragoza, 2007.

Révauger, Cécile y Éric Saunier, eds. La Franc-Maçonnerie Dans Les Ports. Pessac: Presses Universitaires de Bordeaux, 2012.

Solar, Felipe Santiago del. Las logias de Ultramar. En torno a los orígenes de la francmasonería en Chile (1850-1862). Santiago de Chile: Occidente, 2012. 